\title{
The Technology of Obtaining the Highest Possible Result in the Upcoming Match of Top-Level Basketball Teams
}

\author{
Andrey Polozov ${ }^{1,}$, , Arthur Akhmetzyanov² \\ ${ }^{1}$ Department of Physical Education, Ural Federal University, Ekaterinburg, Russia \\ ${ }^{2}$ Department of Physical Education, State Pedagogical University, Surgut, Russia \\ Email address: \\ A.A.Polozov@mail.ru (A. Polozov), 79222570710@yandex.ru (A. Akhmetzyanov) \\ ${ }^{*}$ Corresponding author
}

\section{To cite this article:}

Andrey Polozov, Arthur Akhmetzyanov. The Technology of Obtaining the Highest Possible Result in the Upcoming Match of Top-Level Basketball Teams. American Journal of Sports Science. Vol. 7, No. 1, 2019, pp. 11-19. doi: 10.11648/j.ajss.20190701.13

Received: February 19, 2019; Accepted: March 26, 2019; Published: April 18, 2019

\begin{abstract}
The purpose of this study was to determine the necessary scenario of the upcoming basketball match, which allows to obtain the maximum possible value of the result based on the created technology of modeling PIRS (Polozov Information Rating System). The method of the PIRS can be summarized in the theses. The game consists of a sequence of single combats (game components) and the realization of the moment. The total number of components in basketball is $>50$. The assessment is not focused on the single combats itself, but on its significance for the result. The difference in the score of the game of the team is obtained from these indicators for the players in each component of the game. The player level in the game component is reduced in proportion to the number of single combats. The placement of players is chosen so that the total number of single combats won by the team is maximum. For each minute of the match, the most effective combinations in the attack are determined. They consist of single combats with the greatest advantage of the players of their team. The authors collaborate with the Russian national team in futsal and basketball. A game from Euroleague Olympiakos - Anadolu Efes (87:78) is shown. The limit value of the result for Olympiakos is 107: 30. Subject to the implementation of $50 \%$ of the recommendations, the team will receive $20-30 \%$ wins in addition. The information array of basketball is too large. He cannot be effectively controlled by one trainer. Basketball resource is used by coaches of the top level by $66 \%$. A higher level of results is unattainable for a coach. It requires coordinated interaction of a large group of players for a long period of time. You need to create your own game template for your next opponent and master it in training, rather than using one universal version of the game.
\end{abstract}

Keywords: The Basketball, Rating, Single Combat, Tactics

\section{Introduction}

Is there a maximum result which one team can win another? The answer is objectively positive. You can have no idea where it is, but intuitively we understand that it exists. If it exists, how far is it from the usual level of the game? How close are modern coaches to it? We understand that their capabilities are very modest in this direction. Modern sport is attractive as long as it gives us surprises. If the result in basketball was counted as well as the change in the store, then from this moment it would no longer exist as a phenomenon. If the more affluent clubs on the budget always win everyone, then no one would watch basketball. Sport is beautiful in that it leaves room for a sporting feat. All the layouts change to this value. However, they also change for another reason. This is when the game of one team is maximally or minimally favorable for another. Therefore, to predict the score of the match is so difficult. A person can live up to 120 years. There are examples of people who lived to $116-117$ years. That is, the limit is achievable. We see this on individual examples. In Russia, however, men live up to 60-65 years. We are all used to the fact that $50 \%$ of the limit is the norm. On average, lifetime increases by 3 years every 10 years. We are slowly moving to the limit of our capabilities. And we'll be able to get it after 200 years. However, when the author shows the limit result to the team coach, this usually causes distrust. 
The authors [1] identify the trajectory of the player's movement and they are able to distinguish these trajectories when playing in attack and defense. The algorithm identifies the basic elements of the game and compares them with the stored standards. However, the significance of this work seems a little.

The authors [2] analyzed 40 games of the professional league of Spain. They came to the conclusion about the connection of the result of games with the number of passes, the starting and ending points of movement, used barriers and the duration of possession of the ball. Such data can help to understand how it should have been played in the previous match. But they will be useless in the analysis of the upcoming match where there are other players.

The authors [3] discuss the hierarchical structure of basketball. There they see a strategy, tactics, state of play, role of the player, basic elements and methods of the game, individual tactics. Basketball is perceived as a complex sport activity consisting of an orderly series of tasks in the game. The main achievement of the article is in the formulation of the task. But the main problem of the article is the absence of a rational idea. What basis should a model of the game be to build on? In this article, the basis for the model is the difference in the score created by the player and the team. The difference created by players is added to the final team score. Since you have to play both with your superior opponents (negative difference) and downstream ones (positive difference), then a rating scale is created to display this difference.

The authors [4] analyzed 20 matches of the NSAA the $1^{\text {st }}$ Division of 2013-2014. There is a higher rating of the attacking side compared with the defenders. Winning teams showed a higher percentage of success shots. They also noted the success of the team game with high indexes of the ball selection in the attack and defense.

The authors [5] consider basketball as an object of associative analysis and data analysis based on the Markov process. The small utility of traditional statistical approaches is noted. The elements of the game are: assist, two-point shot, rebound, Steals, three-point shot, free throw, breakthrough, pick and roll, blocked shot. According to the created algorithm the combination of the 1-3 elements in combination gives $50 \%$ efficiency, whereas the combination of 1,2 and $4-$ only $35 \%$. There is a contradiction between a powerful mathematical tool and the poverty of ideas about the structure of the game.

The authors [6] investigated the effectiveness of passes in basketball depending on the position of the player. This element of the game gives $20 \%$ of the match effectiveness. They found strong sequence of passing and receiving movements depending on the position of the players, the zone, the distance of the passage, the defensive. It's not about constructing a passage for a specific player. It is about the general laws of passageways in basketball.

Existing indicators of the player utility. There are a number of competing indicators of the player utility in basketball: coefficient of utility of PBL, KPI, EuroKPI,
Lithuanian KPI, NBA + $\$-, LKPI (Lithuanian KPI) [7].

In the RBF there is a player's utility coefficient which is calculated by the formula: KPI $=$ (points + attacking passes $($ total $)+1.4 *$ steals $+1.2 *$ blocked shots $+1.2 *$ glass +1.4 $*$ alien glass $+0.5 *$ fouls of opponents $-(2$ points brick $)-1.5$ $*$ (3 points brick) $-0.8 *$ (foul points) $-1.4 *$ turnover passes (technical turnover) -fouls)/ played time

EuroKPI (rating for the match) = "positive stats" (points + rebounds + passes + steals + fouls + blocked shots $)$ minus "negative stats" (greased throws (fouls), steals, fouls)

In games NBA is considered PER, which seeks to measure the degree of utility of the player for a minute, according to the pace of the game [8].

$\mathrm{uPER}=1 / \min *(\mathrm{TRIPLES}+[(2 / 3) *$ PASSES $]+[(2-$ factor $*) *($ TEAM PASSES / FINISHED TEAM SHOTS FROM THE GAME)) * FINISHED SHOTS FROM THE GAME $]+$ [FINISHED FREE THROWS*0.5* $(1+(1-$ (TEAM PASSES/ FINISHED TEAM SHOTS FROM THE GAME $))+(2 / 3) *($ TEAM PASSES/ FINISHED TEAM SHOTS FROM THE GAME))] - [VOP * TURNOVERS] [VOP * DRBP * (GAME SHOTS IN TOTAL - FINISHED SHOTS FROM THE GAME)] - VOP * $0.44 *(0.44+(0.56$ * DRBP $)$ * (FREE THROWS IN TOTAL - FINISHED FREE THROWS $)]+[$ VOP * $(1-$ DRBP $) *$ (ALL REBOUNDS - OFFENSIVE REBOUNDS)] + [VOP * DRBP $*$ OFFENSIVE REBOUNDS] + [VOP * STEALS $]+$ [VOP * DRBP * BLOCKED SHOTS] - [FOULS * ((FINISHED FREE THROWS FROM THE LEAGUE / FOULS FROM THE LEAGUE) - $0.44 *$ (ALL FREE THROWS FROM THE LEAGUE / FOULS FROM THE LEAGUE) * VOP))]

PER takes into account positive actions such as shot from the game, foul shot, three-point shots, effective pass, rebounds, blocked shots and steals, and negative ones such as conceded shots, steal a ball and personal comments. The formula adds positive statistics and subtracts negative points through the statistical value system.

$\mathrm{PER}=[\mathrm{UPER} *$ (league pace / team pace $)] *(15 /$ lguPER $)$

The formula is adapted to the pace of the team's game, the playing time of each athlete, and it forms the final rating for the season.

Comprehensive rating of usefulness (CRU): $\mathrm{CRU}=$ $[$ points + rebounds + effective passes + blocked shots + steals + accurate hits (sum of 2 and 3 points and fouls) + fouls of opponents) - (player fouls + losses + shots (amount of 2 and 3-points and fouls)) / number of games] $\mathrm{x}$ (command coefficient).

We chose 10 most important games of the Russian Basketball Championship and calculated them according to all the suggested methods. We were interested in the correlation of the integral coefficient and the actually number of points scored by the team. We were not sure that we could accurately reproduce all aspects of PER. Therefore, we used our own calculations of NBA games with the calculated PER coefficient proposed by Holinger. The correlation coefficient of the game results calculated by the authors was 0.56 . Such low correlation coefficients explain to us why the expert 
coaching assessment still takes precedence over analysts' assessment. However, the information pool called basketball

is too large to be controlled by one coach.

Table 1. Different indicator correlation of the player utility with the game results of VTB united league (Russia).

\begin{tabular}{|c|c|c|c|c|c|c|c|c|}
\hline Play No & Team & KRP & KPI Komsomol pravda & $\mathbf{N B A}+/-$ & KPI & Euro & Lithuania KPI & Score \\
\hline \multirow{2}{*}{1} & Enisey & 144 & 96 & 76 & 0.88 & 0.4 & 0.42 & 83 \\
\hline & CSKA & 87 & 54 & -76 & 0.88 & 0.27 & 0.48 & 65 \\
\hline \multirow{2}{*}{2} & Krasnye Krylia & 90 & 54 & -115 & 0.67 & 0.09 & 0.37 & 67 \\
\hline & Dynamo & 156 & 110 & 115 & 1.02 & 0.66 & -0.07 & 93 \\
\hline \multirow{2}{*}{3} & Krasnye Krylia & 125 & 80 & 25 & 1.08 & 0.49 & 0.28 & 84 \\
\hline & Unics & 142 & 90 & -25 & 0.98 & 0.38 & 0.28 & 81 \\
\hline \multirow{2}{*}{4} & Nizhny Novgorod & 123 & 80 & -16 & 0.96 & 0.08 & 0.57 & 77 \\
\hline & Enisey & 110 & 70 & 16 & 0.85 & 0.26 & 0.36 & 82 \\
\hline \multirow{2}{*}{5} & Nizhny Novgorod & 112 & 66 & -60 & 0.93 & 0.28 & 0.34 & 75 \\
\hline & Khimki & 129 & 82 & 60 & 1.03 & 0.31 & 0.49 & 85 \\
\hline \multirow{2}{*}{6} & Spartak & 101 & 61 & -50 & 0.78 & 0.27 & 0.26 & 64 \\
\hline & Lokomotiv Kuban & 124 & 83 & 50 & 0.91 & 0.36 & 0.24 & 77 \\
\hline \multirow{2}{*}{7} & Triumph & 98 & 59 & -4 & 0.98 & 0.38 & 0.45 & 64 \\
\hline & Dynamo & 100 & 63 & 4 & 0.93 & 0.31 & 0.37 & 65 \\
\hline \multirow{2}{*}{8} & CSKA & 105 & 67 & -16 & 0.99 & 0.24 & 0.32 & 69 \\
\hline & Unics & 101 & 65 & 16 & 1.04 & 0.39 & 0.49 & 71 \\
\hline \multirow{2}{*}{9} & Khimki & 115 & 70 & -23 & 0.94 & 0.3 & 0.28 & 80 \\
\hline & Spartak & 134 & 86 & 23 & 0.99 & 0.39 & 0.22 & 86 \\
\hline \multirow{2}{*}{10} & Nizhny Novgorod & 138 & 93 & 104 & 0.83 & 0.09 & 0.73 & 87 \\
\hline & Krasnye Krylia & 95 & 59 & -104 & 0.87 & 0.31 & 0.2 & 68 \\
\hline \multicolumn{2}{|c|}{ Correlation coefficient } & 0.90 & 0.89 & 0.74 & 0.37 & 0.37 & -0.17 & \\
\hline
\end{tabular}

We can see quite high values of the KRP. But they are based on a more accurate selection of the cost of the indicated components and will be completely different in the NBA. The technology proposed below was also evaluated by correlating the actual result with that obtained from the game structure. It is necessary an explanation here. The algorithm evaluates each single combat during the game according its cost. However, there is this value presumed before the match and actually received. The latter is used in PIRS, but the former is desirable for a correct comparison with opponents. It is usually taken from the previous match of the team. The correlation of 0.93 is explained by the difference between these values.

It was already in 1997 when Polozov AA. published an article [9] which showed the fundamental possibility for the existence of a computer version of an upcoming match. Skorovich S. L., the current coach of the Russian national futsal team, graduated from Institute of Physical Education, Sport and Youth Policy, URFU, in 2003. In that time we collaborated in the work on his diploma thesis. The Russian team has never won against the Spanish national team from 1998 to 2014. Our cooperation continued. The theme of the game modeling was in demand. Today, the national team of Russia has already won over the Spanish national team twice. And there is another leader in the world rating of teams in futsal. Later experience with the team was invested in other game sports.

Why is it difficult for a coach to manage a game? An information pool called handball is too large to be controlled by one coach. If I ask you

"Who is the best and who is the worst player of your team?"- Then the answer is definite.

"Who are the $6^{\text {th }}$ in the level of the game?"- Then the answer is most likely absent.
"Who is the fifth in coordination defeating?" - The answer is especially absent.

"Who is the fifth in the coordination defeating after 10 minutes of the game?" - You unlikely can answer. Etc.

We a priori ascribe to ourselves the ability to finely differentiate the ranking of players according to their game level, but in fact we cannot. Therefore, most of the game remains at the discretion of the players themselves. It's hard to believe that a coach can, for example, say how a player's transfer from one position to another can change a match result, express in one number the tactical effect of the team in the last match. This is beyond the capabilities of the average person. In this situation, coaches-analysts, who usually use Instat, Basketstats, etc., help to a coach. These and other opponents calculate technical and tactical actions (TTA) that have no correlation with the results of games for similar teams. Instat, Basket-stats are not able to answer specific questions. What is the score for this plan of a game? How much less dribbling A player will win from $\mathrm{C}$ one at the beginning of the game and at the end? How many goals will players score from this point of the field from an uncomfortable position? Our conversation with opponents always ends here.

What is the technology being analyzed? The abbreviated name is PIRS (Polozov Information Rating System) [10].

The concept without formulas and terms is presented at rafirst.com. Simplistically, the game consists of a diverse single combat sequence culminating in a shot on goal. The balance of the won and lost single combats in each component in each pair of players is transformed into the game level of each player. This level is reduced from the number of single combats during the game. If you compare this level of players and the upcoming opponent, it allows you to place players in the attack and defense for the maximum number of single combats won. A schedule of substitutions is 
determined for each player, with which of the opponents he plays in defense and attack.

The next step is the recommended exact number of single combats in each component of the game. He does not have to play something that does not fit his abilities. The recommended combinations are formed for each player and his shifts. The most dangerous combinations of the opponent are also highlighted through the position of this player. The algorithm can put a weak player under the exchange with a strong opponent, but gives single combat to other positions. The result of the work is the expected score of the game that must be on the scoreboard when players fulfill all the conditions. We do not form the headache of the coach from the statistics of past games, but already calculated solutions for the best result of the upcoming match.

The purpose of this study is to determine the maximum value of the match result in basketball of the highest level on the basis of the created technology of result simulation. The latter is called Polozov Information Rating System, hereinafter referred to as PIRS.

\section{Method}

Let's consider some problems of game analytics.

The game consists of a single combat sequence allowing you to approach the ring and realize the created moment. To determine the actual value of the cost we should understand how to evaluate the implementation.

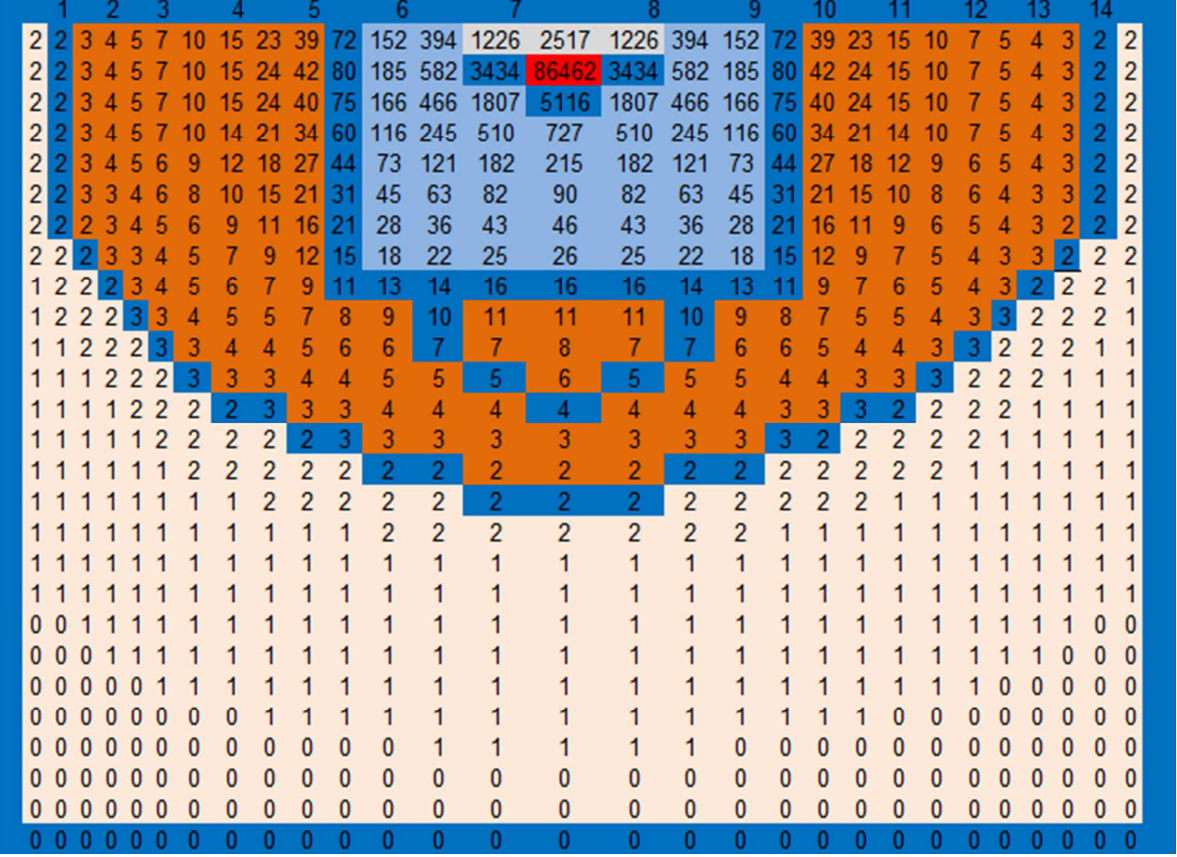

Figure 1. Index values of each point of the field in basketball. The higher the index, the greater the likelihood of a successful throw. [1].

Let's imagine that we are at some point in the field and want to get into the shield. The index of the field point is ratio of the multiplication of $\alpha$ and $\beta$ vertical angles of the view of the shield to the distance to the ring (r):

$$
\varphi=\frac{\alpha * \beta}{r}
$$

There is a link between the probability to score from the given point of the field in this match: $\mathrm{p}=1-(\exp (-\varphi o)$ $A)$ ), where $A=23$ (for Russia). Any action on the field can now be estimated from the increase in this probability. Hereafter, this increase we call the single combat cost. On the other hand, we have to evaluate the player in the implementation of shots. The value of $\mathrm{A}$ is average for the players of this tournament (NBA, etc.). You can calculate the average probability of scoring for each shot of the player in the match. So by the end of the game we will get the expected number of points scored by the average rating and actually scored by the player. The difference between these two figures is the necessary evaluation [11].
We could use the same value of A for different types of shots, but this is an unreasonable decision. There is a paradox here. The player scores 3 points $40 \%$. Then he gets on the penalty line and scores, for example, $77 \%$. It would be logical to expect that from under the ring he will score at least $90 \%$. But in fact this percentage can be twice lower. This is due to the non-standard implementation of shots (one hand, with a deviation, in a collision, etc.). Therefore, 4 types of shots are used - 3 points, 2 points (when throwing the ball are hold with both hands), foul shots and shots from the nonstandard position.

Mixing of technical and tactical actions (TTA) and technical and tactical single combats (TTSC) should be considered as another problem of basketball analysts. TTA can be set up even when the opponent is not on the field at all. As a rule, there is no dribbling at all in different classifications. Although there are a force, coordination and speedy dribbling. Rebound of the ball will be counted even if no one interfered with it. This creates data noise and low correlation. There is the term "active pass" that may not 
involve active opposition from the opponent. Active transfer is often non-registered if the ball is not scored. However, it is absurd to put one player into dependence on the realization of the moment of the other. Also, the foul handling is not always adequate to the game. Foul is a lost single combat. However, its estimation is often wanted to aggravate for the defender. This leads to inadequate operation of the model.

It is necessary to go from TTA estimates to TTSC. They are not less than 30 . These are a pass for the back, dribbling (speed, coordination, and force), control of the ball in a situation when being knocked out, upper single combats, a pass tackling, barriers, etc. There is a forceful, coordinating and speedy dribbling. In addition to these well-known components, there are less actively used such as blocking a shot, restoring a position after a lost single combat, a barrier. TTSC are taken into account only as a loss of the ball and are recorded as an independent component.

The necessity to display the results obtained on an abstract rating scale. If an A player has beaten a B player for 5 out of 10 single combats in one of the components of the game in a match with one team, what will this ratio be in the match with a $\mathrm{C}$ player who plays in the next team on the calendar? We cannot create a model without it. The key consideration is that the difference created by the team consists of the differences created by its players. Therefore, we need to arrange the teams on the scale of the rating at a distance corresponding to their score for a personal meeting. Then the players can be placed on it. A website www.ra-first.com was created, [12] where there was a section on basketball. The current results of all club and national teams were obtained from the relevant sites and then transformed into a rating online. To prove the consistency of the concept the forecast for the next match was formed. The ratings of the teams set the average values of the ratings of its players.

Player's level is transferred into the rating and it is built for each component. The player's rating falls during the game from the number of single combats. But it happens with different speed. There are "light" single combats that are not associated with significant expenditure of energy. There are "heavy" ones. Finding the dynamics of decrease for each component of the game of each player is not a difficulty. The results obtained allow us to redistribute the match load among the players. The load is given to strong players until their level is equal to the level of the others. This mode is called equiparametric. This is the distribution of the number of single combats by players when the largest number of single combats in the match will be won. The player must be given such a distribution in comparison with his usual number of single combats.

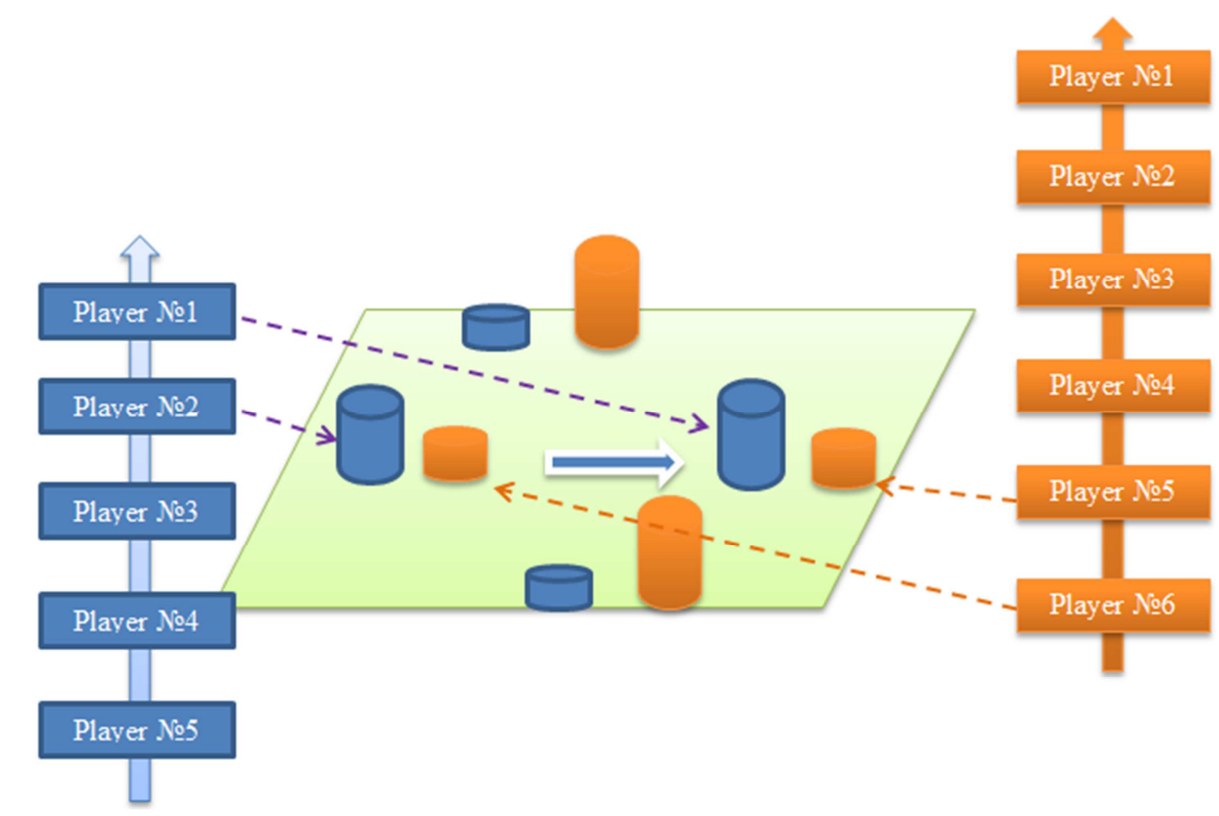

Figure 2. Schematic image. Higher rating values are shown by player height. The algorithm searches for pairs of players with the greatest difference in ratings (height).

Tactical effect. It often happens that a player should collect a number of single combats in defense, but they are not enough on his position. The algorithm moves the player to another position where he will get the necessary number of single combats in this component. As a result, the algorithm rearranges the players throughout the game that gives significantly more won single combats. Accordingly, one must write to the player - when he goes, against whom he plays in the attack and defense. To do this you must use the substitution and placement of the opposing team in the previous match. Then, as a result, a table is formed for each minute of the match with the alignment of the opponent and our team in the attack and defense.

Team combinations. There are about 400 combinations that assume more than $90 \%$ of the overall effectiveness of the game. The combination consists of a sequence of single combats and a shot. The probability to score a goal is equal to the multiplication of the probabilities of winning their single combats, to score from a given point of the field and the number of points awarded for the shot $(1,2$, and 3$)$. 
Probability is formed from a rating that decreases from the number of single combats. Hereafter, under advantageous replacement we mean player single combat with the greatest advantage in the corresponding rating (the greatest chances to win this single combat). The algorithm selects the most advantageous replacement and combines them in combination. The effect of combinations is that the strongest your players do not play with the weakest opponents. This gives an additional increase in the result [5].

\section{Result}

We watched the Euroleague game of Olympiakos Anadolu Efes (87:78) on February 25, 2017. The limit result for Olympiakos is 107:30 [12].

At the same time, the A coefficient was different for 4 kinds of shots: foul shots (9), 2-points (185), 3-points (5.3), 2-point shots from a difficult position, with one hand (1045). It is obviously the teams are well trained to the shots out of the 6-meter line, but the shots from the fight inside it - not the strongest side of both teams.

Table 2. The difference between the match participants in single combats and in the implementation.

\begin{tabular}{|c|c|c|c|c|c|c|c|}
\hline $\mathbf{N}$ & Name & Team & $\begin{array}{l}\text { Won single } \\
\text { combat }\end{array}$ & Lost matches & $\begin{array}{l}\text { Cost of won } \\
\text { single combats }\end{array}$ & $\begin{array}{l}\text { Cost of lost } \\
\text { single combats }\end{array}$ & $\begin{array}{l}\text { The difference } \\
\text { in the balance of } \\
\text { single combat }\end{array}$ \\
\hline 53 & Kirk Alex & Anadolu Efes & 20 & 22 & 55.82 & 11.27 & 44.55 \\
\hline 6 & Papapetrous Ioaniss & Olympiacos & 4 & 10 & 0.76 & 5.63 & -4.87 \\
\hline 1 & Thomas Deshaun & Anadolu Efes & 12 & 14 & 2.66 & 2.12 & 0.54 \\
\hline 9 & Waters Dominic & Olympiacos & 2 & 6 & 3.41 & 8.08 & -4.66 \\
\hline 10 & Agravanis Dimitros & Olympiacos & 6 & 14 & 1.00 & 13.73 & -12.73 \\
\hline 17 & Mantzaris Vengelis & Olympiacos & 23 & 35 & 19.42 & 37.17 & -17.74 \\
\hline 5 & Brown Deric & Anadolu Efes & 34 & 25 & 10.99 & 6.18 & 4.81 \\
\hline 1 & Erick Green & Olympiacos & 16 & 29 & 15.03 & 24.80 & -9.77 \\
\hline 42 & Dunston Bryant & Anadolu Efes & 19 & 38 & 38.10 & 35.12 & 2.98 \\
\hline 11 & Milutinov Nikola & Olympiacos & 21 & 24 & 9.16 & 7.50 & 1.66 \\
\hline 16 & Papanikolaou Kostas & Olympiacos & 28 & 32 & 7.00 & 14.33 & -7.33 \\
\hline 7 & Spanoulis Vassilis & Olympiacos & 76 & 31 & 79.05 & 12.98 & 66.07 \\
\hline 4 & Balbay Dogus & Anadolu Efes & 9 & 8 & 6.38 & 6.09 & 0.29 \\
\hline 2 & Honeycutt Tyler & Anadolu Efes & 20 & 28 & 10.57 & 19.82 & -9.25 \\
\hline 2 & Birch Khem & Olympiacos & 26 & 41 & 17.65 & 22.23 & -4.58 \\
\hline 33 & Paul Brandon & Anadolu Efes & 18 & 19 & 5.88 & 14.54 & -8.66 \\
\hline 6 & Osman Cedi & Anadolu Efes & 22 & 18 & 5.72 & 14.64 & -8.92 \\
\hline 4 & Patric Young & Olympiacos & 8 & 6 & 4.77 & 0.68 & 4.09 \\
\hline 15 & Printezis Georigis & Olympiacos & 35 & 23 & 3.49 & 4.12 & -0.63 \\
\hline 15 & Granger Jayson & Anadolu Efes & 43 & 34 & 7.80 & 34.18 & -26.38 \\
\hline
\end{tabular}

Table 2. Continued.

\begin{tabular}{|c|c|c|c|c|c|c|}
\hline $\mathbf{N}$ & Name & Team & Scored balls, points & Total vs Scored & $\begin{array}{l}\text { Difference in } \\
\text { implementation }\end{array}$ & $\begin{array}{l}\text { The difference in } \\
\text { total on games }\end{array}$ \\
\hline 53 & Kirk Alex & Anadolu Efes & 4 & 4.78 & -0.78 & 43.8 \\
\hline 6 & Papapetrous Ioaniss & Olympiacos & 8 & 4.82 & 3.18 & -0.1 \\
\hline 1 & Thomas Deshaun & Anadolu Efes & 10 & 4.78 & 5.22 & 5.8 \\
\hline 9 & Waters Dominic & Olympiacos & 0 & -0.21 & 0.21 & -4.9 \\
\hline 10 & Agravanis Dimitros & Olympiacos & 1 & -1.66 & 2.66 & -14.4 \\
\hline 17 & Mantzaris Vengelis & Olympiacos & 4 & -4.51 & 8.51 & -22.3 \\
\hline 5 & Brown Deric & Anadolu Efes & 10 & 9.96 & 0.04 & 4.9 \\
\hline 1 & Erick Green & Olympiacos & 10 & 3.10 & 6.90 & -6.7 \\
\hline 42 & Dunston Bryant & Anadolu Efes & 4 & 5.61 & -1.61 & 1.4 \\
\hline 11 & Milutinov Nikola & Olympiacos & 8 & 1.71 & 6.29 & 3.4 \\
\hline 16 & Papanikolaou Kostas & Olympiacos & 8 & -2.11 & 10.11 & -9.4 \\
\hline 7 & Spanoulis Vassilis & Olympiacos & 24 & 1.88 & 22.12 & 68.0 \\
\hline 4 & Balbay Dogus & Anadolu Efes & 0 & 1.16 & -1.16 & -0.9 \\
\hline 31 & Heurtel Thomas & Anadolu Efes & 10 & 9.47 & 0.53 & -8.9 \\
\hline 2 & Honeycutt Tyler & Anadolu Efes & 9 & 7.24 & 1.76 & -7.5 \\
\hline 2 & Birch Khem & Olympiacos & 9 & -0.37 & 9.37 & -4.9 \\
\hline 33 & Paul Brandon & Anadolu Efes & 9 & 12.33 & -3.33 & -12.0 \\
\hline 6 & Osman Cedi & Anadolu Efes & 11 & 11.86 & -0.86 & -9.8 \\
\hline 4 & Patric Young & Olympiacos & 3 & -0.49 & 3.49 & 3.6 \\
\hline 15 & Printezis Georigis & Olympiacos & 14 & -5.71 & 19.71 & -6.3 \\
\hline 15 & Granger Jayson & Anadolu Efes & 10 & 6.3 & 3.72 & -22.7 \\
\hline
\end{tabular}


Table 3. The cost of each single combat won for players of different positions on the court in the match played.

\begin{tabular}{lll}
\hline Position on the court & Olympiacos & Anadolu Efes \\
\hline Cost No 1 & 0.70 & 0.10 \\
Cost No 2 & 0.80 & 0.10 \\
Cost No 3 & 0.10 & 0.40 \\
Cost No 4 & 0.10 & 0.20 \\
Cost No 5 & 0.20 & 1.40 \\
\hline
\end{tabular}

Table 4. Actual and recommended number of single combats for Olympiacos players.

\begin{tabular}{lllll}
\hline Player number & Recommended & Actual & Excess & Change \\
\hline 15 & 98 & 60 & 38 & 7 \\
17 & 66 & 59 & 16 & $\uparrow$ \\
2 & 87 & 71 & 28 & $\uparrow \uparrow$ \\
7 & 140 & 112 & 30 & $\uparrow \uparrow$ \\
16 & 92 & 62 & 24 & 12 \\
11 & 70 & 46 & 30 & $\uparrow$ \\
10 & 32 & 20 & -1 & \\
1 & 75 & 45 & -9 & \\
6 & 13 & 14 & -14 & \\
9 & 0 & 9 & 1 & \\
4 & 0 & 14 & & \\
\end{tabular}

Table 5. The maximum result in matches of different levels.

\begin{tabular}{lllll}
\hline Year & Team & Team & Score & Prediction \\
\hline 2015 & UMMC (Ekat) & PSK (Prague) & $64: 68$ & $86: 68$ \\
2016 & Ural & Ryazan & $65: 66$ & $78: 36$ \\
2017 & Olympiakos & Anadolu & $87: 78$ & $109: 42$ \\
2017 & Russia & Serbia & $78: 87$ & $163: 100$ \\
2017 & Uralmash & Ural & $81: 83$ & $88: 68$ \\
2017 & Uralmash & Irkut & $75: 77$ & $63: 51$ \\
2017 & Uralmash & Apceнал & $64: 86$ & $110: 73$ \\
2017 & Uralmash & MSTU & $120: 70$ & $173: 75$ \\
2017 & Tambov & Uralmash & $59: 50$ & 72 \\
\hline
\end{tabular}

\begin{tabular}{|c|c|c|c|c|c|c|c|c|c|c|c|c|c|c|c|c|c|c|c|c|c|}
\hline 4 & 1 & 2 & 3 & 4 & 5 & 6 & 7 & 8 & 9 & 10 & 11 & 12 & 13 & 14 & 15 & 16 & 17 & 18 & 19 & 20 & 21 \\
\hline 12 & 12 & & 31 & 33 & 2 & 1 & 53 & & 4 & 7 & 1 & 2 & 17 & & 38,0 & 6,3 & & 201 & 4 & & \\
\hline 13 & 13 & & 31 & 6 & 2 & 1 & 53 & & 4 & 7 & 1 & 2 & 9 & & 41,1 & 6,9 & & $292^{\top}$ & $292^{\top}$ & & \\
\hline 14 & 14 & & 31 & 6 & 2 & 1 & 53 & & 4 & 7 & 1 & 2 & 15 & & 44,4 & 7,6 & & 272 & 272 & & \\
\hline 15 & 15 & & 6 & 15 & 2 & 1 & 42 & & 4 & 7 & 1 & 2 & 17 & & 47,7 & 8,5 & & 52 & 106 & & \\
\hline 16 & 16 & & 6 & 15 & 2 & 5 & 42 & & 2 & 7 & 1 & 11 & 17 & & 51,0 & 9,3 & & 212 & & & \\
\hline 17 & 17 & & 6 & 15 & 2 & 5 & 42 & & 4 & 7 & 1 & 2 & 17 & & 54,2 & 10,2 & & 2 & & & \\
\hline 18 & 18 & & 15 & 6 & 2 & 5 & 53 & & 4 & 7 & 1 & 2 & 11 & & 57,5 & 11,1 & & $3^{x}$ & & & \\
\hline 19 & 19 & & 15 & 6 & 2 & 5 & 53 & & 4 & 7 & 1 & 2 & 16 & & 60,7 & 12,0 & & $40^{\top}$ & & & \\
\hline 20 & 20 & & 15 & 6 & 2 & 5 & 42 & & 4 & 7 & 1 & 2 & 17 & & 63,9 & 12,8 & & $128^{\prime}$ & & & \\
\hline 21 & 21 & & 15 & 6 & 2 & 5 & 42 & & 2 & 7 & 1 & 11 & 4 & & 67,2 & 13,6 & & $50^{\top}$ & & & \\
\hline 22 & 22 & & 15 & 31 & 6 & 5 & 53 & & 4 & 7 & 2 & 11 & 15 & & 70,5 & 14,4 & & $69^{\prime}$ & & & \\
\hline 23 & 23 & & 31 & 15 & 6 & 5 & 53 & & 2 & 7 & 9 & 11 & 17 & & 73,6 & 15,3 & & 6 & & & \\
\hline 24 & 24 & & 31 & 33 & 6 & 5 & 53 & & 16 & 7 & 9 & 11 & 17 & & 76,8 & 15,9 & & $95^{x}$ & & & \\
\hline 25 & 25 & & 31 & 33 & 2 & 5 & 53 & & 17 & 7 & 9 & 11 & 15 & & 79,8 & 16,5 & & 292 & & & \\
\hline 26 & 26 & & 31 & 33 & 2 & 5 & 53 & & 11 & 7 & 10 & 9 & 17 & & 82,9 & 17,1 & & 272 & & & \\
\hline 27 & 27 & & 31 & 33 & 2 & 5 & 1 & & 17 & 7 & 9 & 11 & 10 & & 85,9 & 17,7 & & 106 & & & \\
\hline 28 & 28 & & 31 & 15 & 2 & 1 & 5 & & 11 & 7 & 10 & 9 & 16 & & 88,9 & 18,7 & & $52]$ & & & \\
\hline 29 & 29 & & 15 & 6 & 2 & 1 & 5 & & 16 & 7 & 10 & 11 & 17 & & 92,0 & 19,6 & & 2 & & & \\
\hline 30 & 30 & & 15 & 6 & 2 & 1 & 5 & & 17 & 7 & 10 & 11 & 15 & & 95,1 & 20,7 & & 3 & $3^{\pi}$ & & \\
\hline 31 & 31 & & 15 & 6 & 2 & 1 & 42 & & 16 & 7 & 10 & 11 & 17 & & 98,2 & 21,6 & & 202 & 202 & & \\
\hline 32 & 32 & & 15 & 6 & 2 & 1 & 42 & & 16 & 7 & 10 & 11 & 17 & & 101,3 & 22,6 & & $40^{\top}$ & $78^{\prime}$ & & \\
\hline 33 & 33 & & 15 & 6 & 2 & 1 & 42 & & 16 & 7 & 10 & 11 & 15 & & 104,4 & 23,7 & & 4 & 4 & & \\
\hline 34 & 34 & & 31 & 33 & 2 & 1 & 53 & & 4 & 7 & 6 & 2 & 17 & & 105,8 & 24,4 & & $69^{\prime}$ & $69^{\prime}$ & & \\
\hline 35 & 35 & & 15 & 31 & 33 & 5 & 53 & & 2 & 1 & 6 & 7 & 15 & & 106,3 & 25,1 & & 6 & 128 & & \\
\hline 36 & 36 & & 15 & 31 & 33 & 5 & 53 & & 2 & 1 & 6 & 7 & 17 & & 106,4 & 25,8 & & 96 & $50^{\prime}$ & & \\
\hline 37 & 37 & & 15 & 31 & 2 & 5 & 53 & & 4 & 2 & 6 & 7 & 1 & & 106,6 & 26,4 & & 292 & 292 & & \\
\hline 38 & 38 & & 15 & 31 & 2 & 5 & 1 & & 2 & 1 & 6 & 7 & 4 & & 106,8 & 27,0 & & 272 & 272 & & \\
\hline 39 & 39 & & 31 & 33 & 2 & 5 & 1 & & 2 & 1 & 6 & 7 & 9 & & 107,0 & 27,4 & & $106^{7}$ & $106^{\prime \prime}$ & & \\
\hline 40 & 40 & & 31 & 33 & 2 & 5 & 1 & & 2 & 1 & 6 & 7 & 16 & & 107,4 & 27,9 & & $212^{\gamma}$ & 212 & & \\
\hline 41 & & & & & & & & & & & & & & & & & & & & & \\
\hline
\end{tabular}

Figure 3. Shown: minute of the game (1), placement of the opponent (3-7 column), recommended placement of the own team (9-13), expected score of the game $(15,16)$, number of the recommended combination $(18,19)$ with illustration. 


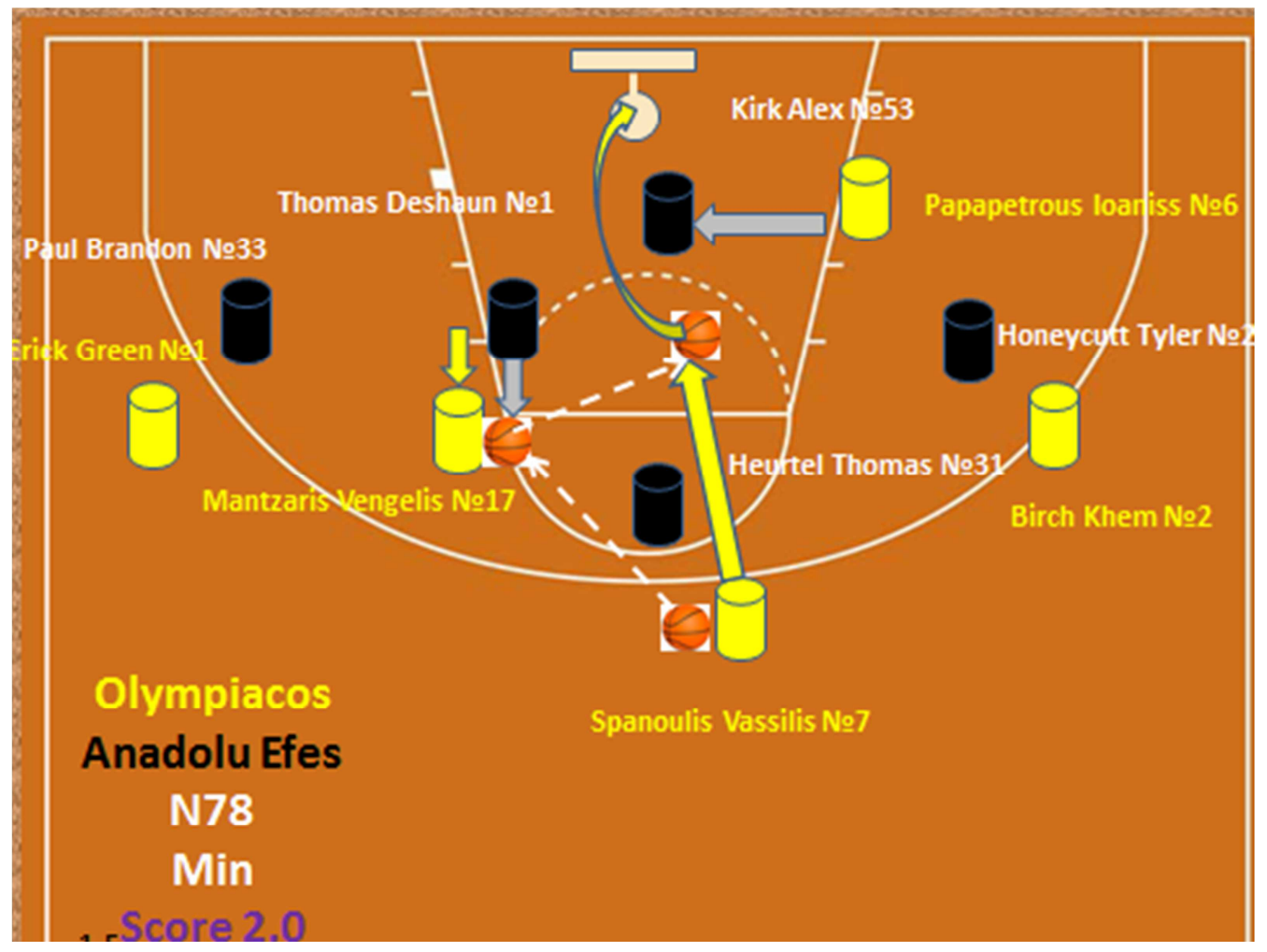

Figure 4. An example of the recommended combination indicating the players of both teams.

As you can see from the presented table the game resource is used only by two thirds in matches of the most different level. This is about 20 to $30 \%$ of additional points when completing assignments by $50 \%$.

\section{Discussion}

There are at least 6 different forms of analytics in basketball. They are designed for sports enthusiasts. There are a number of competing indicators of the player utility in basketball: coefficient of utility of PBL, KPI, EuroKPI, Lithuanian KPI, NBA + $\backslash$-, LKPI (Lithuanian KPI). The paper shows a low level of correlation of these forms with the result of the game. There are other solutions at the club level. In any professional club there is an expert who is engaged in the analytical preparation of the upcoming match. As a rule, the methodology of such specialists is closed. It is not published anywhere. Our correspondence discussion is conducted with them. We compare their expert opinion with the PIRS technology. PIRS acts as an artificial intelligence. The algorithm calculates the limit value of the result of the upcoming match. However, for its implementation there are significant difficulties.

Why is the maximum level practically unattainable?

1. Players may not reproduce their level of play.

2. Players may not remember too much information.

3. Opponent can change his game.

4. The dynamism of the game and the impossibility of its full determinism.

5. Players are used to a certain model of their game in the team, etc.
To overcome all these difficulties it is necessary to create your game model for each next opponent and master it in training. Perhaps, after a while, basketball players will also wear an earpiece on the game through which the coach will tell them what to do next like the stars of TV-series.

\section{Conclusions}

1. Computers are better playing chess and other games than a person. Game sports are next. An information pool called basketball is too large to be effectively controlled by one coach. The resource of the game called basketball is used only by two thirds by the forces of coaches. This unclaimed tactical resource of the game is the limit of the coach possibilities. Now there is the time of information algorithm competition. The competition of coaches turns into a competition of analytical groups.

2. The information rating technology (PIRS) proposed by the authors

a. based on the priority for the game activity difference of goals scored and conceded goals

b. represents a simple universal linear solution of a complex problem

c. allows you to determine the maximum value of the game result with a given opponent based on his placement and distribution of single combats according to the positions of the players.

d. Forms answers in an understandable format of the advantages in the score

There are a number of other competing indicators of the player's utility in basketball: coefficient of utility of PBL, 
KPI, Euro KPI, Lithuanian KPI, NBA $+\backslash-$, LKPI (Lithuanian CPI). But their correlation with the results of games is lower and they do not have such ability to create a computer version of the upcoming match as PIRS [6-10]. Technology is better at the national team level where it is more difficult to work for a coach because of the large number of options to create a team.

3. The maximum result is practically unattainable due to the information complexity in the use of a large group of people. It is necessary to create your game model for each next opponent and master it in training, rather than using one universal version of the game.

\section{References}

[1] A trajectory-based analysis of coordinated team activity in a basketball game./, S. Kovačič, G. Vučkovič, J. Perš / Computer Vision and Image Understanding Volume 113, Issue 5, May 2009, Pages 612-621.

[2] Ball possession effectiveness in men's and women's elite basketball according to situational variables in different game periods / Miguel-Angel Gómez, Alberto Lorenzo, Sergio-José Ibañez \& Jaime Sampaio/ Journal of Sports Sciences Volume 31, 2013 - Issue 14 Pages 1578-1587.

[3] Hierarchical structuration of knowledge in the basketball game / Trninić, Slavko; Trninić, Marko; Jelaska, Igor/ Acta Kinesiologica (1840-2976) 4 (2010), 1; 37-44.
[4] Investigating the game-related statistics and tactical profile in NCAA division I men's basketball games. / Conte, Daniele; Tessitore, Antonio; Gjullin, Aaron; Mackinnon/ Biology of Sport. 2018, Vol. 35 Issue 2, p 137-143. 7p.

[5] Technical and Tactical Analysis of Basketball Match based on Data Mining/ Ming Zi, Dan Gao/ Boletín Técnico, Vol. 55, Issue 16, 2017, pp. 518-523.

[6] Inside game ball transitions according to player's specific positions in NBA basketball /J. Courel Ibáñez, E. Suárez Cadenas, D. Cárdenas Vélez/ Cuadernos de Psicología del Deporte Vol. 17, Núm. 3 (2017).

[7] Burov I. V, Polozov A. A., Alternative statistical accompaniment of basketball matches / Journal of Scientific Problems of Humanitarian Studies No 11 - 2011. P. 90. ISSN 2071-9175.

[8] Polozov A. A. "The rating system in the game sports...". USTU-UPI, Ekaterinburg, 1995, 206 p.

[9] Polozov A. A. The upcoming match. Computer version / Theory and practice... 1997 - No 3.

[10] Polozov A. A. Rating in sport: yesterday, today, tomorrow.Moscow: Soviet sport, $2007-316$ p.

[11] Handbook of Ratings. Approaches to Ratings in the Economy, Sports, and Society / A. Karminsky. A. Polozov/ International Publishing house "Springer", 2016., 360c. 